\title{
The Influence of Negative Pressure in High-Position Tunnel on Gas Grainage Effect
}

\author{
Jianliang Gao ${ }^{1,2,3}$, Longyu Zhuang ${ }^{3}$, Weilong Ding ${ }^{3}$ \\ ${ }^{1}$ The Collaborative Innovation Center of Coal Safety Production of Henan Province \\ Jiaozuo, China \\ gao@hpu.edu.cn; zhuanglongyu@163.com; 1305266714@qq.com \\ ${ }^{2}$ State Key Laboratory Cultivation Base for Gas Geology and Gas Control \\ Jiaozuo, China \\ ${ }^{3}$ Henan Polytechnic University, Jiaozuo, China
}

\section{Extended Abstract}

Based on the simulation results of the airflow field and gas distribution when high-position tunnel is used to extract the gas in goaf, air leakage between the working face and the goaf, gas distribution in goaf and upper corner, gas quantity drained out by high-position tunnel are analyzed under the different extraction negative pressure $P$ in high-position tunnel. The conclusions are demonstrated as follows:

(1) With the increase of negative extraction pressure $P$, the scope of air leakage from working face to goaf along with working face changes slightly if $P$ is less than $5 \mathrm{kPa}$, and the scope of air leakage increases gradually when $P$ is higher than $5 \mathrm{kPa}$. Air leaks from the whole length of the working face into goaf if $P$ is over $17 \mathrm{kPa}$.

(2) With the rise of negative extraction pressure $P$, volume of air leakage from working face to goaf basically doesn't change if $\mathrm{P}$ is lower than $7 \mathrm{kPa}$, and it increases linearly if $P$ is higher than $7 \mathrm{kPa}$. With the rise of negative extraction pressure $P$, volume of air leakage from goaf to working face reduces linearly if $P$ is lower than $7 \mathrm{kPa}$, and it's reduction amplitude decreases gradually if $P$ is higher than $7 \mathrm{kPa}$.

(3) Gas concentration reduces slightly at air inlet side of goaf, it reduces rapidly at air return side of goaf, and gas concentration at upper corner reduces with the rise of negative extraction pressure $P$, Gas accumulation problem at upper corner can be solved if $P$ rises to $3 \mathrm{kPa}$.

(4) Gas concentration in high-position tunnel reduces and the pure methane quantity increases with the rise of negative pressure $P$. When the negative pressure is higher than $17 \mathrm{kPa}$, all gas emitted into goaf is drained out through high-position tunnel.

\section{References}

[1] Y. Shaohong and Y. Xiwen, "Discussing about the main theoretical problems of long wall with top coal caving," Journal of China Coal Society, vol. 33, pp. 481-484, 2008.

[2] Y. Shaohong, Y. Xiwen, X. Hongjie, "Roof structure of short cantilever-articulated rock beam and calculation of support resistance in full-mechanized face with large mining height," Journal of China Coal Society, vol. 36, pp. 1816-1820, 2011.

[3] W. Guofa, P. Yihui, L. Junfeng, "Determination and influence of cutting height of coal by top coal caving method with great mining height in extra thick coal seam," Journal of China Coal Society, vol. 37, pp. 1777-11782, 2012.

[4] W. Jinhua, "Key technology for fully-mechanized top coal caving with large mining height in extra-thick coal seam," Journal of China Coal Society, vol. 12, pp. 2089-2098, 2013.

[5] M. Xianrui, W. Hongpeng, L. Hhaohui et al, "Selection principle and development status of thick seam mining methods in China," Coa Science and Technology, vol. 37, pp. 39-44, 2009.

[6] W. Cheng, "Numerical simulation study on reasonable gas extraction negative pressure in the High-level entry," Industrial Safety and Environmental Protection, vol. 37, pp. 59-61, 2011. 